\title{
Selectivity and specificity of sphingosine 1-phosphate receptor ligands: "off-targets" or complex pharmacology?
}

\section{Nigel J. Pyne* and Susan Pyne}

Cell Biology Group, Strathclyde Institute of Pharmacy and Biomedical Sciences, University of Strathclyde, Glasgow, UK

\section{Edited by:}

Maria Angela Sortino, University of

Catania, Italy

Reviewed by:

Armando A. Genazzani, Università del

Piemonte Orientale, Italy

Dagmar Meyer Zu Heringdorf,

Klinikum der Goethe-Universität

Frankfurt am Main, Germany

Kevin Lynch, University of Virginia,

USA

\section{${ }^{*}$ Correspondence:}

Nigel J. Pyne, Cell Biology Group,

Strathclyde Institute of Pharmacy and

Biomedical Sciences, University of

Strathclyde, 161 Cathedral Street,

Glasgow G4 ORE, UK.

e-mail:n.j.pyne@strath.ac.uk
A recent perspective published in Frontiers of Pharmacology by Salomone and Waeber (2011) discussed the selectivity and specificity of sphingosine 1-phosphate (S1P) receptor ligands. This perspective surveyed the use of various S1P receptor ligands and attempted to reconcile a number of inconsistencies in the predicted biological outcomes: these were interpreted as "off-target" effects. Therefore the perspective cautioned against the use of these S1P receptor ligands. Here we highlight the complex pharmacology of S1P receptors, which along with "inside-out" signaling might provide an alternative explanation for "off-target" effects.

Keywords: sphingosine 1-phosphate, JTE-013, BML-241, VPC23019, CAY10444

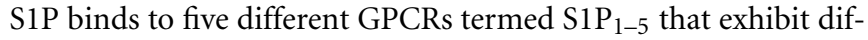
ferential coupling to various G-protein sub-types (Pyne and Pyne, 2010). The perspective by Salomone and Waeber (2011) focused on three S1P receptor ligands, JTE-013, BML-241 (CAY10444), and VPC23019. The major issues raised by these authors related to the findings that JTE-013 (which has been characterized as an $\mathrm{S}_{1} \mathrm{P}_{2}$ receptor antagonist; Osada et al., 2002; Ohmori et al., 2003) inhibited not only the vasoconstrictor effect of S1P, but also that of the prostanoid analog U46619, endothelin-1, or high $\mathrm{KCl}$ (Salomone et al., 2008). In addition, BML-241 (which has been characterized as an $\mathrm{S} 1 \mathrm{P}_{3}$ receptor antagonist; Koide et al., 2002) inhibits increases in intracellular calcium mediated by $\mathrm{P}_{2}$ receptor or $\alpha_{1 \mathrm{~A}}$-adrenoceptor stimulation and reduces $\alpha_{1 \mathrm{~A}}$-adrenoceptor stimulated contraction of mesenteric artery, while it failed to prevent the $\mathrm{S}_{1} \mathrm{P}_{3}$-mediated reduction in forskolin-stimulated cyclic AMP accumulation (Jongsma et al., 2006). Moreover, VPC23019 (characterized as an $\mathrm{S}_{1} \mathrm{P}_{1 / 3}$ antagonist; Davis et al., 2005) unexpectedly potentiated S1P-stimulated contraction in intact basilar arteries (Salomone et al., 2008); a result confounded by the finding that S1P-stimulated vasoconstriction was reduced in tissue from

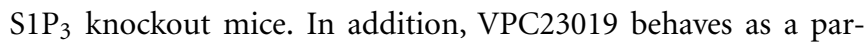
tial agonist in a $\mathrm{S} \mathrm{P}_{3}$ calcium mobilization assay (Jongsma et al., 2009). These anomalies are used to suggest that "off-target" effects should be seriously considered as caveats to conclusions drawn, unless validated by siRNA knock down or genetic knock out of the S1P receptor being studied. If applied at sufficient concentrations, all small molecules are likely to have "off-target" effects. The issue here is that for the ligands mentioned above, none of the "off-targets" have been definitively identified, and we do not know whether a sufficient concentration has been reached. In addition, critical analysis requires defining the precise GPCR ligand pharmacology for these reagents before a definitive appraisal of "off-target" effects can be made. In this regard, the pharmacology of GPCRs is not simple, and is made more complicated by the fact that an array of different conformational states of the same receptor might exist, each of which might bind ligands with markedly different affinities. Moreover, the different conformational states of a GPCR might also be differentially coupled to distinct G-proteins. Several examples of this critically important complex ligand pharmacology are discussed here.

FTY720 (or fingolimod) is an immunosuppressant that was very recently licensed by the Food and Drug Administration and the European Medicines Agency as Gilenya ${ }^{\mathrm{TM}}$. This sphingosine analog is taken up by cells, phosphorylated by sphingosine kinase 2 (SK2) and released as FTY720 phosphate. FTY720 phosphate binds to and activates $\mathrm{S}_{1} \mathrm{P}_{1}, \mathrm{~S}_{1} \mathrm{P}_{3}, \mathrm{~S}_{1} \mathrm{P}_{4}$, and $\mathrm{S}_{1} \mathrm{P}_{5}$, but not $\mathrm{S}_{1} \mathrm{P}_{2}$ (Brinkmann et al., 2010). FTY720 phosphate also induces a later "functional antagonism" by promoting the polyubiquitination, endocytosis, and proteasomal degradation of $\mathrm{S}_{1} \mathrm{P}_{1}$ (Gräler and Goetzl, 2004), which creates $\mathrm{S}_{1} \mathrm{P}_{1}$ receptor null T-cells to induce lymphopenia. In contrast, $\mathrm{S}_{1} \mathrm{P}_{1}$ receptors recycle in response to S1P. Therefore, S1P and FTY720 phosphate do not appear to bind to and stabilize the same conformation of $\mathrm{S}_{1} \mathrm{P}_{1}$. These different conformational states are likely to exist in equilibrium, as binding of FTY720 phosphate to a specific $\mathrm{S}_{1} \mathrm{P}_{1}$ conformation will increase its concentration by mass action such that the entire population of $\mathrm{S}_{1} \mathrm{P}_{1}$ will be eventually degraded in response to FTY720 phosphate, and this is indeed the case (Figure 1A).

The concept that different conformational states of S1P receptors might exist is very important in terms of explaining the unusual pharmacology of receptor ligands that could otherwise be interpreted as "off-target" effects. For instance, FTY720 phosphate 


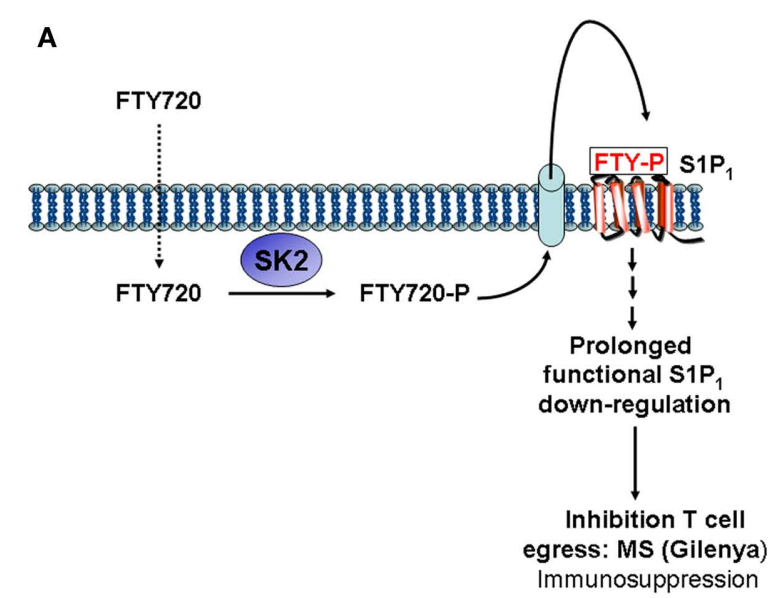

B

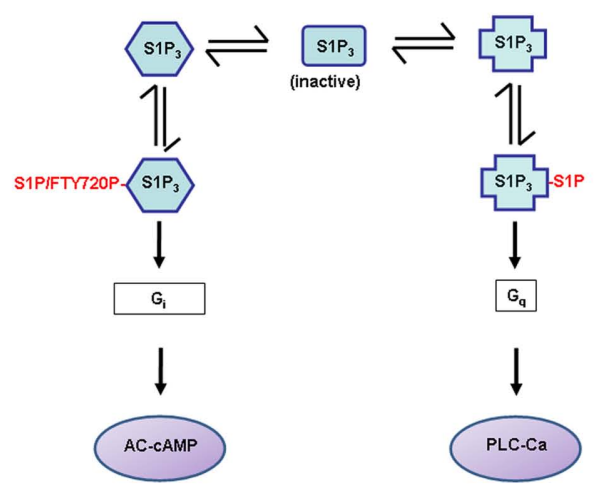

C

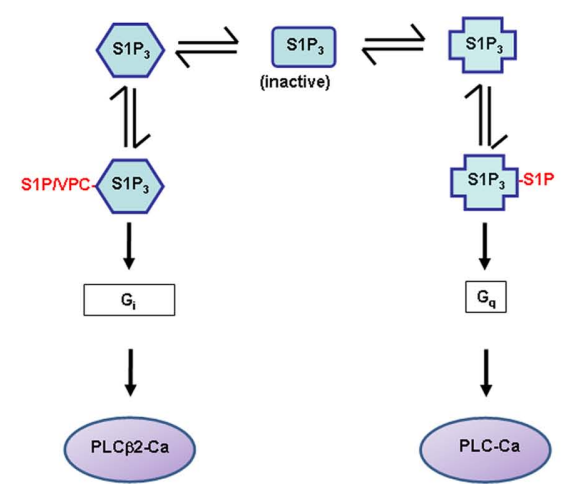

FIGURE 1 | (A) Phosphorylation of FTY720 by sphingosine kinase 2 (SK2) and release to induce down-regulation of $\mathrm{S}_{1} \mathrm{P}_{1}$. (B) and (C) Equilibrium transition model showing the binding of S1P, FTY720 phosphate (FTY720P), or VPC23019 (VPC) to the conformational states (denoted by different shapes) of $\mathrm{S} \mathrm{P}_{3}$ coupled to different $\mathrm{G}$-proteins. The positions of the equilibrium in $\mathbf{B}, \mathbf{C})$ will be affected by binding of S1P, FTY720P, or VPC23019 to the different conformations of $\mathrm{S} \mathrm{P}_{3}$ but are not represented here for simplicity. The ligands are shown in red.

binds to and activates a specific $\mathrm{S}_{1} \mathrm{P}_{3}-\mathrm{G}_{\mathrm{i}}$ coupled receptor conformation and inhibits $\mathrm{S}_{1} \mathrm{P}_{3}-\mathrm{G}_{\mathrm{q}}$ coupled receptor signaling (Sensken et al., 2008). These findings can be explained by a model in which $\mathrm{S}_{1} \mathrm{P}_{3}-\mathrm{G}_{\mathrm{q}}$ and $\mathrm{S}_{\mathrm{P}} \mathrm{P}_{3}-\mathrm{G}_{\mathrm{i}}$ are in equilibrium. Thus, FTY720 phosphate may act as a "biased agonist" by binding exclusively to the $\mathrm{S} \mathrm{P}_{3}-\mathrm{G}_{\mathrm{i}}$ conformation which would reduce the concentration of the $\mathrm{S} \mathrm{P}_{3}-\mathrm{G}_{\mathrm{q}}$ receptor conformation by mass action and thereby inhibit $\mathrm{S}_{1} \mathrm{P}_{3}-\mathrm{G}_{\mathrm{q}}$ signaling (Figure 1B). Therefore, it is possible that BML-241 is also a "biased" agonist of the $\mathrm{S}_{1} \mathrm{P}_{3}-\mathrm{G}_{\mathrm{i}}$ conformation that regulates adenylyl cyclase and thus, an antagonist of $\mathrm{S} \mathrm{P}_{3}-\mathrm{G}_{\mathrm{q}}$ signaling. If this is the case, then one would not necessarily expect BML-241 to prevent an $\mathrm{S} 1 \mathrm{P} / \mathrm{S}_{1} \mathrm{P}_{3}$-mediated inhibition of forskolin-stimulated cyclic AMP accumulation.

We have evaluated the effect of BML-241 (CAY10444) on $\mathrm{S}_{2} \mathrm{P}_{2}$, $\mathrm{S}_{3} \mathrm{P}_{3}$, and $\mathrm{S}_{1} \mathrm{P}_{4}$ each separately over-expressed in HTC4 cells. Our findings demonstrate that BML-241 inhibited S1P/S1P $\mathrm{P}_{3}$-mediated calcium mobilization in a concentration-dependent manner with a $\sim 80 \%$ inhibition at $10 \mu \mathrm{M}$ BML-241. BML-241 had no effect on S1P-stimulated calcium responses mediated by $\mathrm{S}_{2} \mathrm{P}_{2}$ or $\mathrm{S}_{4} \mathrm{P}_{4}$ (Long et al., 2010a). Although, BML-241 is a low potency antagonist of $\mathrm{S}_{1} \mathrm{P}_{3}$, the extent to which it reduces $\mathrm{S} 1 \mathrm{P}$-stimulated calcium mobilization in HTC4 cells over-expressing $\mathrm{S}_{1} \mathrm{P}_{3}$ is superior to that reported by Koide et al. (2002). Further support for an action of BML-241 on $\mathrm{S}_{3} \mathrm{P}_{3}$ was obtained by our findings that S1P stimulation of ERK-1/2 in MCF-7 breast cancer cells is abolished by BML-241 and this is recapitulated by siRNA knockdown of $\mathrm{S}_{3} \mathrm{P}_{3}$ (Long et al., 2010b). Interestingly, S1P stimulation of ERK-1/2 in MCF-7 cells is reduced by pertussis toxin, indicating involvement of $\mathrm{S} \mathrm{P}_{3}-\mathrm{G}_{\mathrm{i}}$ (Sukocheva et al., 2006). This might suggest increased complexity in the behavior of BML-241 which appears to antagonize a conformation of $\mathrm{S} \mathrm{P}_{3}-\mathrm{G}_{\mathrm{i}}$ that is coupled to the ERK-1/2 pathway in MCF-7 cells.

BML-241 inhibits increases in intracellular calcium mediated by $\mathrm{P}_{2}$ receptor or $\alpha_{1 \mathrm{~A}}$-adrenoceptor stimulation in $\mathrm{CHO}$ cells and reduces $\alpha_{1 \mathrm{~A}}$-adrenoceptor stimulated contraction of mesenteric artery (Jongsma et al., 2006). However, the possibility that stimulation of these receptors activates sphingosine kinase (catalyzes synthesis of S1P from sphingosine) to promote S1P synthesis and release, which can then act on local $\mathrm{S} 1 \mathrm{P}$ receptors (e.g., $\mathrm{S}_{\mathrm{P}} \mathrm{P}_{3}$ ) in the artery (termed "inside-out" signaling), cannot be excluded at this time. Indeed, we have also shown that BML-241 inhibits S1P- and anandamide-induced relaxation of endothelium intact coronary artery vessels (by blocking the "inside-out" signaling by $\mathrm{S} 1 \mathrm{P}$ in response to anandamide). The latter is also reduced by VPC23019 (Mair et al., 2010), while W146, an S1P 1 selective antagonist (Wamhoff et al., 2008) had no effect (Mair et al., 2010). In addition to "inside-out" signaling, the alternative possibility that $\mathrm{P}_{2}$ or $\alpha_{1 \mathrm{~A}}$-adrenoceptors might form functional heterodimers with $\mathrm{S}_{1} \mathrm{P}_{3}$ and that BML-241 induces allosteric effects on $\mathrm{P}_{2}$ or $\alpha_{1 \mathrm{~A}}$-adrenoceptor-mediated signaling via $\mathrm{S}_{1} \mathrm{P}_{3}$ has not been excluded.

JTE-013 (Ohmori et al., 2003) is widely used as a $\mathrm{S}_{2} \mathrm{P}_{2}$ antagonist in vitro and is effective in vivo, reducing streptozotocininduced apoptosis of pancreatic $\beta$ cells and incidence of diabetes (Imasawa et al., 2010) and IgE-triggered anaphylactic responses (Oskeritzian et al., 2010). Both of these disease models are attenuated in $\mathrm{SIP}_{2}^{-/-}$mice, thereby supporting a role for this receptor type, and the action of JTE-013 at $\mathrm{S}_{\mathrm{P}}$. As pointed out by Salomone and Waeber (2011), JTE-013 inhibited the specific binding of radiolabeled S1P with an $\mathrm{IC}_{50}$ of $17 \pm 6$ and $22 \pm 9 \mathrm{nM}$ in $\mathrm{CHO}$ cells over-expressing human or rat recombinant $\mathrm{S}_{1} \mathrm{P}_{2}$ respectively, and had no effect on $\mathrm{S}_{1} \mathrm{P}_{1}$ or $\mathrm{S}_{1} \mathrm{P}_{3}$ at concentrations in excess of $10 \mu \mathrm{M}$ (Ohmori et al., 2003). We confirmed that JTE-013 
inhibited S1P-stimulated calcium mobilization with an $\mathrm{IC}_{50}$ of $\sim 1 \mu \mathrm{M}$ in HTC4 cells over-expressing $\mathrm{S}_{1} \mathrm{P}_{2}$, with no significant effect on S1P-stimulated calcium mobilization in HTC4 cells overexpressing $\mathrm{S} \mathrm{P}_{3}$ at concentrations as high as $10 \mu \mathrm{M}$ (Long et al., 2010a). However, we also demonstrated that JTE-013 is not specific for $\mathrm{S}_{1} \mathrm{P}_{2}$, and inhibits $\mathrm{S} 1 \mathrm{P}$-stimulated calcium mobilization in HTC4 cells over-expressing $\mathrm{S} \mathrm{P}_{4}$ with a $\mathrm{Ki}$ of $237 \mathrm{nM}$ (Long et al., 2010a). Moreover, S1P stimulation of ERK-1/2 in MDA-MB-453 breast cancer cells, which express endogenous $\mathrm{S}_{2} \mathrm{P}_{2}$ and $\mathrm{S}_{1} \mathrm{P}_{4}$, was inhibited by JTE-013 $(10 \mu \mathrm{M})$ and this was recapitulated by siRNA knockdown of $\mathrm{S}_{1} \mathrm{P}_{4}$, but not $\mathrm{S}_{2} \mathrm{P}_{2}$ (Long et al., 2010a).

The ability of JTE-013 to antagonize $\mathrm{S}_{1} \mathrm{P}_{4}$ might provide an alternative explanation for the finding that JTE-013 inhibits S1Pinduced vasoconstriction in $\mathrm{SIP}_{2}^{-/-}$mice (Salomone and Waeber, 2011). Although $\mathrm{S}_{1} \mathrm{P}_{4}$ is reported to have a rather restricted tissue distribution confined to immune cells, this may not be the case as evidenced by its expression in breast cancer cells (Long et al., 2010a) or, alternatively, heterogenous tissue preparations may contain inflammatory cells that release vasoconstrictors in response to $\mathrm{S} 1 \mathrm{P}$, mediated by $\mathrm{S}_{\mathrm{P}}$. JTE-013 also inhibited prostanoid-, endothelin 1-, and $\mathrm{KCl}$-induced contraction, the latter suggesting perturbation of L-type calcium channel activity (Salomone et al., 2008). However, vasoconstriction of the basilar artery to prostanoid and $\mathrm{KCl}$ is reduced in $\mathrm{SK} 1^{-/-}$mice (Salomone et al., 2010). Furthermore, we found that JTE-013 had no significant inhibitory effect on S1P-stimulated calcium mobilization in HTC4 cells over-expressing $\mathrm{S}_{3} \mathrm{P}_{3}$ (Long et al., 2010a) suggesting that JTE-013 $(10 \mu \mathrm{M})$ has no activity on $\mathrm{S}_{3} \mathrm{P}_{3}$ or calcium signaling down-stream of S1P receptors.

To highlight the complexity of the pharmacology of S1P receptor ligands, we point to SB649146 (Waters et al., 2006; Pyne and

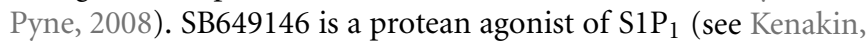
2001 for review of protean agonism). SB649146 exhibits inverse agonism by reducing $S_{1} P_{1}$-mediated $G_{i}$ activation, competitive antagonism of S1P (displaces dihydro S1P (an $\mathrm{S}_{1} \mathrm{P}_{1}$ agonist) and inhibits S1P-stimulated activation of ERK-1/2 in airway smooth muscle cells) and is a partial agonist when used alone, e.g., SB649146 weakly stimulates the pertussis toxin-sensitive ERK1/2 pathway in airway smooth muscle cells (Waters et al., 2006). The effect of SB649146 is mediated by binding to $\mathrm{S}_{1} \mathrm{P}_{1}$ in airway smooth muscle cells because treatment of these cells with an antisense oligonucleotide specific for $\mathrm{S} \mathrm{P}_{1}$ abolished $\mathrm{S} 1 \mathrm{P}$-stimulated activation of ERK-1/2 (Waters et al., 2003). SB649146 also induces endocytosis of a relatively small pool of $\mathrm{S}_{1} \mathrm{P}_{1}$ in airway smooth muscle cells, consistent with a partial agonistic effect on $\mathrm{S}_{1} \mathrm{P}_{1}$, but inhibits S1P-stimulated endocytosis/signaling of $\mathrm{S}_{1} \mathrm{P}_{1}$ (Waters et al., 2006).

The action of VPC23019 (which was initially described as an $\mathrm{S}_{1} \mathrm{P}_{1 / 3}$ antagonist, Davis et al., 2005) as an $\mathrm{S}_{1} \mathrm{P}_{3}$ agonist on calcium signaling (Jongsma et al., 2009) might also be explained by complexities in GPCR pharmacology. In this regard, Jongsma et al. (2009) have demonstrated that VPC23019 reduces forskolinstimulated cAMP accumulation in CHO cells over-expressing $\mathrm{S}_{3} \mathrm{P}_{3}$ suggesting that it might function as an agonist by binding to and stabilizing the $\mathrm{S}_{1} \mathrm{P}_{3}-\mathrm{G}_{\mathrm{i}}$ conformation. Moreover, VPC23019 stimulated calcium mobilization, a response that was sensitive to pertussis toxin and thus possibly also mediated by $\mathrm{S}_{1} \mathrm{P}_{3} / \mathrm{G}_{\mathrm{i}}$ and a $\mathrm{G}_{\mathrm{i}} \beta \gamma$-regulated PLC $\beta 2$-dependent mechanism (Figure 1C). Crucially, the effect of VPC23019 on S1P-stimulated calcium mobilization (to establish whether it inhibits $\mathrm{S}_{1} \mathrm{P}_{3}-\mathrm{G}_{\mathrm{q}}-$ mediated calcium signaling) was not tested. Therefore, the potentiating effect of VPC23019 on S1P-induced vasoconstriction described by Salomone and Waeber (2011) might also be explained by biased agonism at $\mathrm{S}_{1} \mathrm{P}_{3}-\mathrm{G}_{\mathrm{i}}$ and stimulation of PLC $\beta 2 /$ calcium signaling, although this requires formal investigation. This interpretation is not at odds with the data obtained using $\mathrm{SIP}_{3}^{-/-}$mice, where S1P-stimulated calcium mobilization by both $\mathrm{G}_{\mathrm{i}}$ and $\mathrm{G}_{\mathrm{q}}$ signaling routes would be ablated.

Davis et al. (2005) demonstrated that VPC23019 competitively inhibited S1P-stimulated GTP $\gamma S$ binding in membranes from HEK 293T cells transiently over-expressing $\mathrm{S}_{3} \mathrm{P}_{3}$ together with mutated $\mathrm{C} 352 \mathrm{~F}$ mutated $\mathrm{G}_{\mathrm{i} 2} \alpha, \beta 1$, and $\gamma 2$. However, it should be stated that Davis et al. (2005) did not observe any agonistic effect of VPC23019 in their assay system. In addition, VPC23019 competitively antagonized S1P-stimulated calcium mobilization in T24 cells stably over-expressing $\mathrm{S}_{3} \mathrm{P}_{3}$ (Davis et al., 2005) and displaced radiolabeled $\mathrm{S} 1 \mathrm{P}$ binding to $\mathrm{S}_{1} \mathrm{P}_{1}$ or $\mathrm{S} 1 \mathrm{P}_{3}$ receptors in HEK 293 T cells. Therefore, differences found in the two studies appear to be centered around the $\mathrm{S}_{1} \mathrm{P}_{3}$ pharmacology in the different assay systems used. TY-52156, a selective $\mathrm{S}_{1} \mathrm{P}_{3}$ antagonist restores coronary blood flow that was reduced by $\mathrm{S} 1 \mathrm{P}$, and inhibits Rho dependent activation and calcium signaling (Murakami et al., 2010 ), suggesting that it does not discriminate between $\mathrm{S}_{1} \mathrm{P}_{3}$ receptor conformations. This contrasts with VPC23019 which has no effect on coronary flow (Murakami et al., 2010), possibly because it might not antagonize $\mathrm{S}_{1} \mathrm{P}_{3}$-Rho conformational signaling. In the same study, VPC23019 was shown to inhibit Eu-GTP binding in membranes from cells over-expressing $\mathrm{S}_{1} \mathrm{P}_{3}$. It should also be noted that TY-52156 has been used in only one study to date and is also an $\mathrm{S1P}_{4}$ antagonist (Murakami et al., 2010). VPC23019 is a phosphorylated lipid and is therefore a possible substrate for lipid phosphate ectophosphatases (LPP, for review see Pyne et al., 2005). Therefore, LPP activity might limit availability of VPC23019 at S1P receptors, and this might account for differences in pharmacology in certain cellular systems dependent on the expression level of LPP. VPC23019 is also a full agonist of $\mathrm{S} \mathrm{P}_{4}$ and a partial agonist of $\mathrm{S}_{1} \mathrm{P}_{5}$ (Davis et al., 2005) and this may complicate interpretation of its effects in heterogenous tissue preparations.

Salomone and Waeber (2011) also state that "off-target" effects of FTY720 are not likely relevant to the clinical action of FTY720 (via FTY720 phosphate), which occur at nanomolar concentrations in terms of inducing lymphopenia. This is compared with micromolar concentration effects of FTY720 on SK1 (Tonelli et al., 2010), ceramide kinase (Lahiri et al., 2009), 14-3-3 protein (Woodcock et al., 2010), acid sphingomyelinase (Dawson and Qin, 2011), and phospholipase A2 (Payne et al., 2007). There are two important points here. FTY720 has to be taken up into cells, so that it can be phosphorylated by SK2 to form FTY720 phosphate. The $\mathrm{Km}$ of SK2 for FTY720 is $18.2 \mu \mathrm{M}$ (Billich et al., 2003). Thus, we suspect that FTY720 has to be concentrated by the cell to bring its concentration into the micromolar substrate range so that it 
can be used by SK2 to form FTY720 phosphate. Notably, the Ki for SK1 inhibition by FTY720 is $2 \mu \mathrm{M}$ (Lim et al., 2011) and this is therefore close to the concentration of FTY720 that might be expected to accumulate within cells from an extracellular nM concentration. Second, FTY720 and FTY720 phosphate have opposing actions. Thus, the treatment of human cancer cells (MCF-7, MDAMB-231, and Sk-Br-3 cells) with FTY720 inhibits growth, activates JNK, and transiently inhibits ERK-1/2 activation with no effect on p38 MAPK in MCF-7 cells. In contrast, FTY720 phosphate induces growth of these cells (Nagaoka et al., 2008). FTY720 demonstrates significant anti-cancer activity in vivo, and apoptosis of cancer cells, and this is therefore likely to be directly related to inhibition of SK1, an enzyme which is known to play a critical role in promoting cancer cell survival (Pyne and Pyne, 2010). Therefore, one can legitimately question whether SK1, PLA2, etc., are indeed, "off-targets."

Clearly, screening is required to test the selectivity and specificity of ligands for receptors and enzymes, related targets and "off-targets." However, in the absence of identified "off-targets" that can explain the observed pharmacology, the alternative possibilities centered around the complexities of GPCR pharmacology must also be considered. Therefore, the purpose of this perspective is to bring these issues to the attention of the research community so that GPCR pharmacology versus "off-target" effects can be tested experimentally in the future. In addition, Salomone and Waeber (2011) cite many studies concerning the use of JTE-013,

\section{REFERENCES}

Billich, A., Bornacin, F., Devay, P., Mechtcheriakova, D., Urtz, N., and Baumruker, T. (2003). Phosphorylation of the immunomofulatory drug, FTY720 by sphingosine kinase. J. Biol. Chem. 278, 47408-47415.

Brinkmann, V., Billich, A., Baumrauker, T., Heining, P., Schmouder, R., Francis, G., Aradhyve, S., and Burton, P. (2010). Fingolimod (FTY720): discovery and development of an oral drug to treat multiple sclerosis. Nat. Rev. Drug Discov. 9, 883-897.

Davis, M. D., Clemens, J. J., Macdonald, T. L., and Lynch, K. R. (2005). Sphingosine 1-phosphate analogs as receptor antagonists. J. Biol. Chem. 280, 9833-9841.

Dawson, G., and Qin, J. (2011). Gilenya (FTY720) inhibits acid sphingomyelinase by a mechanism similar to tricy-clic antidepressants. Biochem. Biophys. Res. Commun. 404, 321-323.

Gräler, M. H., and Goetzl, E. J. (2004). The immunosuppressant FTY720 down-regulates sphingosine 1-phosphate G-protein coupled receptors. FASEB J. 18, 551-553.

Imasawa, T., Kioke, K., Ishi, I., Chun, J., and Yatomi, Y. (2010). Blockade of sphingosine 1-phosphate receptor 2 signalling attenuates streptozotocininduced apoptosis of pancreatic beta-cells. Biochem. Biophys. Res. Commun. 392, 207-211.

Jongsma, M., Hendriks-Balk, M. C., Michel, M. C., Peters, S. L., and Alewijnse, A. E. (2006). BML-241 fails to display selective antagonism at the sphingosine-1-phosphate receptor, S1P(3). Br. J. Pharmacol. 149, 277-282.

Jongsma, M., van Unen, J., van Loenen, P. B., Michel, M. C., Peters, S. L., and Alewijnse, A. E. (2009). Different response patterns of several ligands at the sphingosine1-phosphate recep-tor subtype 3 (S1P3). Br. J. Pharmacol. 156, 1305-1311.

Kenakin, T. (2001). Inverse, protean, and ligand-selective agonism: matters of receptor conformation. FASEB J. 15, 598-611.

Koide, Y., Hasegawa, T., Takahashi, A., Endo, A., Mochizuki, N., Nakagawa, M., and Nishida, A. (2002). Development of novel EDG3 antagonists using a 3D database search and their structure- activity relationships. J. Med. Chem. 45, 4629-4638.

Lahiri, S., Park, H., Laviad, E. L., Lu, X., Bittman, R., and Futerman, A. H. (2009). Ceramide synthesis is

BML-241, and VPC23019 that have not been validated by genetic deletions or eliminations. However, lack of validation of an effect of a given S1P receptor ligand does not immediately invalidate the conclusion drawn. Moreover, genetic deletions or siRNA elimination are also not without "off-target" effects, especially as GPCRs exist in constitutively active states and/or are regulated by autocrine ligands to induce signaling pathways that regulate gene expression. Some of the genes regulated by genetic deletions or eliminations of GPCRs might induce an effect which is not recapitulated by an acute action of an antagonist. We ascribe to a combined approach using pharmacological ligands and molecular tools to validate specificity (Waters et al., 2003; Long et al., 2010a,b). However, a wider panel of receptor ligands is also required to add power to the validation process and one should be aware of limitations in interpretation of molecular approaches if complexities in the GPCR ligand pharmacology are not fully defined.

In our opinion, multiple assays should be used (e.g., ligand binding, GTP $\gamma S$ binding, calcium, cAMP, $\beta$-arrestin, and ERK-1/2 activation) to characterize competitive antagonism, biased agonism, and protean agonism. The knowledge of which signaling effectors are controlled by the various conformational states of a given S1P receptor should then inform on the appropriate use of defined pharmacological agents to interrogate a biological system. This approach should also enhance information gained from genetic knockout or elimination studies.

modulated by the sphingosine ana$\log$ FTY720 via a mixture of uncompetitive and noncompetitive inhibition in an Acyl-CoA chain lengthdependent manner. J. Biol. Chem. 284, 16090-16098.

Lim, K. G., Tonelli, F., Li, Z., Lu, X., Bittman, R., Pyne, S., and Pyne, N. J. (2011). FTY720 analogues as sphingosine kinase 1 inhibitors: Enzyme inhibition kinetics, allosterism, proteasomal degradation and actin rearrangement in MCF-7 breast cancer cells. J. Biol. Chem. 286, 18633 18640.

Long, J. S., Fujiwara, Y., Edwards, J., Tannahill, C., Tigyi, G., Pyne, S., and Pyne, N. J. (2010a). Sphingosine 1-phosphate 4 uses HER2 (ErbB2) to regulate extracellular signal regulated kinase-1/2 in MDA-MB-453 breast cancer cells. J. Biol. Chem. 285, 35957-35966.

Long, J. S., Edwards, J., Watson, C. Tovey, S., Mair, K., Schiff, R., Natarajan, V., Pyne, N. J., and Pyne, S. (2010b). Sphingosine kinase 1 induces tolerance to human epidermal growth factor receptor 2 and prevents formation of a migratory phenotype in response to sphingosine 1-phosphate in estrogen receptor positive breast cancer cells. Mol. Cell. Biol. 30, 3827-3841.
Mair, K., Robinson, E., Kane, K., Pyne, S., Brett, R., Pyne, N. J., and Kennedy, S. (2010). Interaction between anandamide and sphingosine-1-phosphate in mediating vasorelaxation in rat coronary artery. Br. J. Pharmacol. 161, 176-192.

Murakami, A., Takasugi, H., Ohnuma, S., Koide, Y., Sakurai, A., Takeda, S., Hasegawa, T., Sasamori, J., Konno, T., Hayashi, K., Watanabe, Y., Mori, K., Sato, Y., Takahashi, A., Mochizuki, N., and Takakura, N. (2010). Sphingosine 1-phosphate (S1P) regulates vascular contraction via S1P3 receptor: investigation based on a new S1P3 receptor antagonist. Mol. Pharmacol. 77, 704-713.

Nagaoka, Y., Otsuki, K., Fujita, T., and Uesato, S. (2008). Effects of phosphorylation of immunomodulatory agent FTY720 (fingolimod) on antiproliferative activity against breast and colon cancer cells. Biol. Pharm. Bull. 6, 1177-1181.

Ohmori, T., Yatomi, Y., Osada, M., Kazama, F., Takafuta, T., Ikeda, H., and Ozaki, Y. (2003). Sphingosine 1-phosphate induces contraction of coronary artery smooth muscle cells via S1P2. Cardiovasc. Res. 58, 170-177. 
Osada, M., Yatomi, Y., Ohmori, T., Ikeda, H., and Ozaki, Y. (2002). Enhancement of sphingosine 1-phosphate-induced migration of vascular endothelial cells and smooth muscle cells by an EDG-5 antagonist. Biochem. Biophys. Res. Commun. 299, 483-487.

Oskeritzian, C. A, Price, M. M., Hait, N. C., Kapitonov, D., Falanga, Y. T., Morales, J. K., Ryan, J. J., Milstein, S., and Spiegel, S. (2010). Essential roles of sphingosine-1phosphate receptor 2 in human mast cell activation, anaphylaxis, and pulmonary edema. J. Exp. Med. 207, 465-474.

Payne, S. G., Oskeritzian, C. A., Griffiths, R., Subramanian, P., Barbour, S. E., Chalfant, C. E., Milstien, S., and Spiegel, S. (2007). The immunosuppressant drug FTY720 inhibits cytosolic phospholipase A2 independently of sphingosine-1phosphate receptors. Blood 109, 1077-1085.

Pyne, N. J., and Pyne, S. (2008). Sphingosine 1 phosphate, lysophosphatidic acid and growth factor signalling and termination. Biochim. Biophys. Acta 1781, 467-476.

Pyne, N. J., and Pyne, S. (2010). Sphingosine 1 phosphate and cancer. Nat. Rev. Cancer 10, 489-503.

Pyne, S. Long, J. S., Ktistakis, N. T., and Pyne, N. J. (2005). Lipid phosphate phosphatases and lipid phosphate signalling. Biochem. Soc. Trans. 33, 1370-1374.

Salomone, S., Potts, E. M., Tyndall, S., Ip, P. C., Chun, J., Brinkmann, V., and Waeber, C. (2008). Analysis of sphingosine 1-phosphate receptors involved in constriction of isolated cerebral arteries with receptor null mice and pharmacological tools. Br. J. Pharmacol. 153, 140-147.

Salomone, S., Soydan, G., Ip, P. C., Hopson, K. M., and Waeber, C. (2010). Vessel-specific role of sphingosine kinase 1 in the vasoconstriction of isolated basilar arteries. Pharmacol. Res. 62, 465-474.

Salomone, S., and Waeber, C. (2011). Selectivity and specificity of sphingosine-1-phosphate receptor ligands: caveats and critical thinking in characterizing receptor-mediated effects. Front. Pharmacol. 2:9. doi: 10.3389/fphar.2011.00009

Sensken, S. C, Stäubert, C., Keul, P., Levkau, B., Schoneberg, T., and Gräler, M. H. (2008). Selective activation of Gai-mediated signalling of S1P3 by FTY720 phosphate. Cell. Signal. 20, 1125-1133.

Sukocheva, O., Wadham, C., Holmes, A., Albanese, N., Verrier, E., Feng, F., Bernal, A., Derian, C. K, Ullrich, A., Vadas, M. A., and Xia, P. (2006). Estrogen transactivates EGFR via the sphingosine 1-phosphate receptor Edg-3: the role of sphingosine kinase-1. J. Cell. Biol. 173, 301-310.

Tonelli, F., Lim, K. G., Loveridge, C., Long, J., Pitson, S. M., Tigyi, G., Bittman, R., Pyne, S., and Pyne, N. J. (2010). FTY720 and (S)-FTY720 vinylphosphonate inhibit sphingosine kinase 1 and promotes its proteasomal degradation in human pulmonary artery smooth muscle, breast cancer and androgenindependent prostate cancer cells. Cell. Signal. 22, 1536-1542.

Wamhoff, B. R., Lynch, K. R., Macdonald, T. L., and Owens, G. K. (2008). Sphingosine-1-phosphate receptor subtypes differentially regulate smooth muscle cell phenotype. Arterioscler. Thromb. Vasc. Biol. 28, 1454-1461.

Waters, C., Sambi, B., Kong, K.-C., Thompson, D., Pitson, S. M., Pyne, S., and Pyne, N. J. (2003). Sphingosine 1-phosphate and plateletderived growth factor (PDGF) act via PDGFbeta receptor-sphingosine 1-phosphate receptor complexes in airway smooth muscle. J. Biol. Chem. 278, 6282-6290.

Waters, C. M., Long, J. S., Gorshkova, I., Fujiwara, Y., Connell, M. C., Belmonte, K. E., Tigyi, G., Natarajan, V., Pyne, S., and Pyne, N. J. (2006). Cell migration activated by platelet-derived growth factor receptor is blocked by an inverse agonist of the sphingosine 1-phosphate receptor-1. FASEB J. 20, 509-511.

Woodcock, J. M., Ma, Y., Coolen, C., Pham, D., Jones, C., Lopez, A. F., and Pitson, S. M. (2010). Sphingosine and FTY720 directly bind pro-survival 14-3-3 proteins to regulate their function. Cell. Signal. 22, 1291-1299.

Conflict of Interest Statement: The authors declare that the research was conducted in the absence of any commercial or financial relationships that could be construed as a potential conflict of interest.

Received: 06 April 2011; accepted: 20 May 2011; published online: 31 May 2011.

Citation: Pyne NJ and Pyne S (2011)

Selectivity and specificity of sphingosine 1-phosphate receptor ligands: "off-targets" or complex pharmacology?. Front. Pharmacol. 2:26. doi: 10.3389/fphar.2011.00026

This article was submitted to Frontiers in Experimental Pharmacology and Drugs Discovery, a specialty of Frontiers in Pharmacology.

Copyright (c) 2011 Pyne and Pyne. This is an open-access article subject to a nonexclusive license between the authors and Frontiers Media SA, which permits use, distribution and reproduction in other forums, provided the original authors and source are credited and other Frontiers conditions are complied with. 